\title{
Análise do perfil de textura do Physalis angulata L desidratado osmoticamente
}

\author{
${ }^{*}$ Semirames do Nascimento Silva, ${ }^{1}$ Newton Carlos dos Santos, ${ }^{2}$ Raphael Lucas Jacinto Almeida, ${ }^{1}$ Sâmela Leal Barros, \\ ${ }^{1}$ Virgínia Mirtes de Alcântara Silva, ${ }^{1}$ Josivanda Palmeira Gomes \\ ${ }^{* 1}$ Universidade Federal de Campina Grande, semirames.agroecologia@gmail.com; \\ newtonquimicoindustrial@gmail.com; samelaleal7@gmail.com; virginia.mirtes2015@gmail.com; josivanda \\ $\underline{\text { gmail.com }}^{2}$ Universidade Federal do Rio Grande do Norte, raphaelqindutrial@gmail.com.
}

\begin{abstract}
RESUMO: A textura, juntamente com a aparência e o sabor, constituem os três atributos de qualidade que estabelecem a aceitabilidade de um alimento pelo consumidor. Portanto, o presente trabalho tem como objetivo realizar a desidratação osmótica do Physalis angulata L. e determinar o seu perfil de textura antes e após o processo de desidratação. Os frutos foram submetidos ao processo de desidratação osmótica em solução de sacarose nas concentrações de 45, 50, 55 e $60^{\circ}$ Brix com agitação mecânica de $100 \mathrm{rpm}$ na temperatura de $60{ }^{\circ} \mathrm{C}$. Para a obtenção dos parâmetros mecânicos de textura foi empregado o teste de resistência à compressão com o auxílio do probe P/36, onde os frutos in natura e desidratados foram avaliados quanto aos seguintes atributos através do diagrama de tensãodeformação: firmeza $(\mathrm{N})$, coesividade, gomosidade $(\mathrm{N})$ e mastigabilidade $(\mathrm{J})$. Para todos os parâmetros avaliados, os maiores valores foram obtidos para os frutos desidratados a $60^{\circ}$ Brix e os menores para os frutos in natura. Através dos dados obtidos por meio dos parâmetros de textura, conclui-se que a concentração de sacarose foi diretamente proporcional aos parâmetros avaliados no presente estudo. No qual já era esperado visto que a saída de água do fruto, faz com que as fibras e os materiais insolúveis se concentrem, elevando os parâmetros de textura. A aceitabilidade do consumidor é influenciada pelos parâmetros de textura que fazem parte da análise sensorial. Dentre as amostras analisadas a com menor porcentagem de sacarose no processo de desidratação osmótico se destacou, por se assemelhar mais com os parâmetros da fruta in natura.
\end{abstract}

PALAVRAS-CHAVE: Firmeza; Mastigabilidade; Sacarose; Sólidos solúveis. INTRODUÇÃO

O gênero Physalis pertence à família Solanaceae, distribuída em regiões temperadas, quentes e subtropicais. As espécies comumente encontradas no Brasil são a Physalis peruviana e angulata, sendo o Rio Grande do Sul o principal produtor desses frutos "in natura" (PAGOT; HOFFMANN, 2003). Dentre as técnicas de produção de alimentos que constituem os princípios agroecológicos, uma das mais importantes é a produção orgânica, especialmente devido ao compromisso desse tipo de produção em oferecer alimentos saudáveis aos consumidores, livres de venenos que comprometem a saúde dos mesmos (DAMO, 2012).

O fruto do Physalis é pequeno e redondo, apresenta polpa que varia de amarela até um escuro alaranjado semelhante em tamanho, forma e estrutura ao tomate, envolto parcial ou completamente por um invólucro parecido com um balão, conhecido por cálice, contendo o fruto em seu interior e centenas de pequenas sementes (ALVARADO et al., 2004).

Sobre as vantagens nutricionais e de palatabilidade dos alimentos de origem agroecológica quando comparados aos fornecidos pelo agronegócio, quando cultivados de maneira convencional, os produtos agrícolas podem conter substâncias tóxicas potencialmente indutoras de vários tipos de doenças. A qualidade nutricional e o sabor desses alimentos muitas vezes também são alterados. A produção de alimentos de maneira ecológica é feita sem a utilização de agrotóxicos e em solos com intensa atividade biológica, em harmonia com o meio do cultivo. Os alimentos agroecológicos tendem a apresentar melhor qualidade nutricional e sabor, e também se conservam melhor do que os produtos da agricultura convencional (CRIVELLARO et al., 2008).

Esses frutos apresentam compostos bioativos que contribuem para a captura de radicais livres atuando como antioxidantes (FONTANA et al., 2000). No entanto, alguns estudos verificaram perdas dos compostos termossensíveis após o processamento da fruta, devido à aplicação de métodos de secagem convencionais, que geralmente são associados à redução da qualidade nutricional, funcional e sensorial dos produtos (OLIVARES et al., 2017).

A fim de se reduzir substancialmente os efeitos negativos ocasionados pela secagem, vários pré-tratamentos térmicos podem ser aplicados, e um deles é a desidratação osmótica, pois além de reduzir os efeitos da secagem, agrega maior sabor e valor ao produto final (LANDIM et al., 2016). O processo de desidratação osmótica consiste na imersão do produto em uma solução hipertônica de sais ou açúcar, em que o gradiente de pressão existente entre a solução e a fruta promove a ocorrência de três fluxos de massa simultâneos: perda de água do fruto para a solução, migração de solutos da solução para o fruto e perda de alguns sólidos solúveis presentes na fruta, como açúcar, minerais e muitos outros nutrientes (LUCHESE et al., 2015). Através do processo de desidratação osmótica, torna-se possível a melhoria na qualidade do produto final, redução dos custos de energia e o desenvolvimento de novos produtos (OZDEMIR et al., 2016).

Caderno Verde de Agroecologia e Desenvolvimento Sustentável (ISSN 2358-2367) v. 9, n.7, e-6831, 2019 doi: $10.18378 /$ cvads.v9i7.6831 
SILVA, S. N. et al. Análise do perfil de textura do Physalis angulata L desidratado osmoticamente. In: II Congresso Paraibano de Agroecologia \& IV Exposição Tecnológica, 2019. Anais... Caderno Verde de Agroecologia e Desenvolvimento Sustentável, Pombal, v. 9, n.7, e-6831, 2019.

Nesse contexto, objetivou-se realizar a desidratação osmótica do Physalis angulata L e determinar o seu perfil mecânico de textura antes e após o processo de desidratação.

\section{MATERIAL E MÉTODOS}

\section{Local da pesquisa}

O experimento foi realizado no Laboratório de Propriedades Físicas da Unidade Acadêmica de Engenharia de Alimentos do Centro de Tecnologia e Recursos Naturais e no Laboratório de Engenharia Bioquímica do Centro de Ciência Tecnologia na Universidade Federal de Campina Grande. Foram utilizados como matéria-prima o physalis $(P$. angulata L) maduros. Os frutos foram selecionados, lavados em água corrente e sanitizados em água clorada (100 ppm) por $15 \mathrm{~min}$.

\section{Desidratação osmótica}

Para a preparação da solução osmótica foi utilizada água destilada e sacarose comercial, obtendo-se separadamente os seguintes teores de sólidos solúveis $\left(45,50,55\right.$ e $60{ }^{\circ}$ Brix), pré-aquecidas e utilizando uma proporção de 1:5 (fruto: solução). Os frutos de physalis foram pesados e imersos na solução osmótica em frascos Erlenmeyer (250 $\mathrm{mL}$ ), em seguida foram encaminhados a incubadora com agitação mecânica de 100rpm (TE-421 da marca Tecnal) na temperatura de $60{ }^{\circ} \mathrm{C}$ por $5 \mathrm{~h}$.

\section{Perfil de textura}

Para a obtenção dos parâmetros dos perfis de textura instrumental do fruto do physalis in natura e desidratados foi empregado o teste TPA (Texture Profile Analysis) em Texturômetro TAXT plus (Stable Micro Systems). Para a obtenção dos parâmetros foi empregado o teste de resistência à compressão com o auxílio do probe P/36R, cilindro de alumínio com diâmetro de $36 \mathrm{~mm}$ a uma tensão sobre $80 \%$ da amostra, força de contato de $1 \mathrm{~N}$, distância de retorno de $20 \mathrm{~mm}$ e a velocidade de retorno de 1,0 mms-1. No perfil de textura, os atributos estudados foram firmeza (N), coesividade, gomosidade $(\mathrm{N})$ e mastigabilidade $(\mathrm{J})$ seguindo a metodologia de Giongo et al., 2019. Valores esses retirados do diagrama de tensão-deformação apresentado pelo equipamento.

\section{Análise estatística}

Os dados foram avaliados estatisticamente, através de um delineamento inteiramente casualizado, por meio de análise de variância e teste de Tukey a 5\% de probabilidade utilizando-se o programa estatístico ASSISTAT versão 7.7 beta (SILVA; AZEVEDO, 2016).

\section{RESULTADOS E DISCUSSÃO}

Na Tabela 1 encontram-se os valores de textura instrumental para os parâmetros firmeza (N), coesividade (adimensional), gomosidade $(\mathrm{N})$ e mastigabilidade (J) para os frutos de Physalis, obtidos por desidratação osmótica em solução osmótica de $45,50,55$ e $60^{\circ}$ Brix na temperatura de $60{ }^{\circ} \mathrm{C}$.

Tabela 1. Teste de TPA (Texture Profile Analysis) do physalis in natura e desidratado a 45, 50, 55 e $60{ }^{\circ} \mathrm{Brix}$ na temperatura de $60^{\circ} \mathrm{C}$.

\begin{tabular}{|c|c|c|c|c|c|}
\hline \multicolumn{2}{|c|}{ Amostras } & Firmeza $(\mathbf{N})$ & Coesividade & Gomosidade (N) & Mastigabilidade (J) \\
\hline \multicolumn{2}{|c|}{ In natura } & $216,13^{\mathrm{e}}$ & $0,174^{\mathrm{d}}$ & $100,97^{\mathrm{c}}$ & $101,30^{\mathrm{d}}$ \\
\hline \multirow{4}{*}{$\begin{array}{c}\text { Desidratação } \\
\text { osmótica }\end{array}$} & $45^{\circ}$ Brix & $312,50^{\mathrm{d}}$ & $0,289^{\mathrm{c}}$ & $147,25^{b}$ & $128,30^{\mathrm{cd}}$ \\
\hline & $50{ }^{\circ}$ Brix & $345,97^{\mathrm{c}}$ & $0,312^{\mathrm{c}}$ & $156,32^{b}$ & $143,77^{\mathrm{c}}$ \\
\hline & $55^{\circ}$ Brix & $378,50^{\mathrm{b}}$ & $0,449^{\mathrm{b}}$ & $166,97^{\mathrm{b}}$ & $157,14^{\mathrm{b}}$ \\
\hline & $60^{\circ}$ Brix & $494,43^{\mathrm{a}}$ & $0,560^{\mathrm{a}}$ & $249,61^{\mathrm{a}}$ & $169,25^{\mathrm{a}}$ \\
\hline
\end{tabular}

As médias seguidas pela mesma letra na mesma coluna, não diferem estatisticamente entre si. Foi aplicado o de Tukey ao nível de $5 \%$ de probabilidade.

Avaliando a firmeza, pôde-se observar que as maiores forças encontradas foram nos frutos desidratados, com a variação de firmeza entre a $216,13 \mathrm{~N}$ a $494,43 \mathrm{~N}$, para ambos os frutos (in natura e desidratados), observou-se também que maiores forças foram necessários conforme teve um aumento do teor de sólidos solúveis, ou seja, as amostras que necessitaram de menor força foram as in natura e as desidratadas com $45^{\circ}$ Brix e $50{ }^{\circ}$ Brix, apresentando as forças de $216,13 \mathrm{~N} ; 312,50 \mathrm{~N} ; 345,97 \mathrm{~N}$, respectivamente. Fato este também observado por Queiroz et al. (2007) ao desidratarem 
SILVA, S. N. et al. Análise do perfil de textura do Physalis angulata L desidratado osmoticamente. In: II Congresso Paraibano de Agroecologia \& IV Exposição Tecnológica, 2019. Anais... Caderno Verde de Agroecologia e Desenvolvimento Sustentável, Pombal, v. 9, n.7, e-6831, 2019.

goiabas. É perceptível a diferença significativa nos valores de acordo com o grau de desidratação para todas as amostras. Diferentemente do que foi encontrado por Miranda et al. (2015), ao analisar a firmeza nas passas de goiaba os tratamentos estudados não apresentaram diferença significativa. Esta firmeza elevada do material ocorre pela maior incorporação do açúcar no processo osmótico, o que pode ser uma condição importante e desejável no desenvolvimento de novos produtos prontos para consumo ou como ingrediente em bolos, sorvetes e iogurte, dentre outros (MIRANDA et al., 2015). E segundo Silva et al. (2019) a textura, a aparência e o sabor, constituem os três atributos de qualidade que estabelecem a aceitabilidade de um alimento pelo consumidor.

A coesividade apresentou uma variação de 0,174 a 0,560 entre o Physalis in natura e os desidratados, observa-se comportamento de aumento no valor à medida que ocorreu a elevação do ${ }^{\circ}$ Brix. Sendo que os maiores valores encontrados foram observados para os frutos submetidos à solução de 60 Brix. A coesão é um parâmetro que reflete a tolerância danos e a integridade da amostra. Sua definição sensorial é a força de contração interna da amostra (BELGHITH FENDRI et al. 2016). Não é indicado para esse parâmetro valores extremos, pois a aceitabilidade do consumidor é influenciado pelo mesmo. Para a gomosidade observou-se que as variações nos valores encontrados foram entre 100,97 a 249,61N. O mesmo perfil da coesividade foi encontrado para a gomosidade, no qual a desidratação osmótica com soluções de ${ }^{\circ}$ Brix maior elevou o parâmetro. Não foi visto diferenças significativas segundo o teste de Tukey para as amostras desidratadas com 45, 50 e $55^{\circ}$ Brix. Segundo Bolzan e Pereira (2017), a gomosidade é um parâmetro secundário, associado à firmeza e coesividade e sua variação é reflexo destas. É perceptível que a coesividade e a gomosidade são influenciadas pela desidratação devido à saída de água do fruto, o que faz com que as fibras e os materiais insolúveis se concentrem.

Os resultados da mastigabilidade sofreram a influência dos tratamentos osmóticos, onde se pôde observar uma variação entre 101,30 a 169,25J. O maior valor encontrado foi para o fruto submetido à solução com $60{ }^{\circ}$ Brix, e o menor valor encontrado foram para o fruto in natura (sem desidratação), seguindo o comportamento apresentado pela textura da firmeza, coesividade e gomosidade. Os valores não apresentaram diferenças significativas entre a amostra in natura e a desidratada a $45^{\circ} \mathrm{Brix}$, assim como as desidratadas a 45 e $50{ }^{\circ} \mathrm{Brix}$. Estudos recentes realizados por Missang et al. (2012), mostraram que a textura das frutas desidratadas depende amplamente da estrutura do tecido e composição da parede celular.

\section{CONCLUSÕES}

Os dados obtidos por meio dos parâmetros firmeza, coesividade, gomosidade e mastigabilidade apresentaram o mesmo comportamento mecânico de textura, onde a concentração de sacarose foi diretamente proporcional ao aumento nos parâmetros avaliados, se assemelhando assim aos dados presentes na literatura. A aceitabilidade do consumidor é influenciada pelos parâmetros de textura que fazem parte da análise sensorial. Dentre as amostras analisadas a com menor porcentagem de sacarose no processo de desidratação osmótico se destacou, por se assemelhar mais com os parâmetros da fruta in natura.

\section{REFERÊNCIAS}

ALVARADO, P. A.; BERDUGO, C. A.; FISCHER, G. Efecto de um tratamiento a 1,5 ${ }^{\circ} \mathrm{C}$ y dos humedades relativas sobre las características físico-químicas de fruto de uchuva Physalis peruviana L. durente el posterior transporte y almacenamiento. Agronomía Colombiana, v.22, p.147-159, 2004.

BELGHITH FENDRI, L.; CHAARI, F.; MAALOUL, M.; KALLEL, F.; ABDELKAFI, L.; ELLOUZ CHAABOUNI, S.; GHRIBI-AYDI, D. Wheat bread enrichment by pea and broad bean pods fibers: Effect on dough rheology and bread quality. LWT, v. 73, p. 584-591, 2016.

BOLZAN, A. B.; PEREIRA, E. A. Elaboração e caracterização de doce cremoso de caqui com adição de sementes da araucária. Brazilian Journal of Food Technology, v. 20, p.1-11, 2017.

CRIVEllaro, C. V. L; CASTEll, C. H. G. P; SIllVEIRA, I. M. L; SILVA, K. G; CARVALHO, R. V; GROSSKOPF, T. A. C. Agroecologia: um caminho amigável de conservação da natureza e valorização da vida. Núcleo de Educação e Monitoramento Ambiental - NEMA. Rio Grande: NEMA, 2008.

DAMO, A. Algumas considerações sobre agroecologia e produção orgânica de alimentos. Ambiente \& Educação, v. 17, n. 1, p. 139-154, 2012.

FOnTANA, J. D.; MENDES, S. V.; VERSIKE, D. S.; PERACETTA, L. F.; PASSOS, M. Carotenóides: Cores atraentes e ação biológica. Revista biotecnologia Ciência e Desenvolvimento, v. 2, p. 40-45, 2000.

GIONGO, L.; AJELLI, M.; PONCETTA, P.; RAMOS-GARCÍA, M.; SAMBO, P.; FARNETI, B. Raspberry texture mechanical profiling during fruit ripening and storage. Postharvest Biology and Technology, v.149, p.177-186, 2019. 
SILVA, S. N. et al. Análise do perfil de textura do Physalis angulata L desidratado osmoticamente. In: II Congresso Paraibano de Agroecologia \& IV Exposição Tecnológica, 2019. Anais... Caderno Verde de Agroecologia e Desenvolvimento Sustentável, Pombal, v. 9, n.7, e-6831, 2019.

LANDIM, A. P. M.; BARBOSA, M. I. M. J. I.; JÚNIOR, J. L. B. Influence of osmotic dehydration on bioactive compounds, antioxidante capacity, color and texture of fruits and vegetables: a review. Revista Ciência Rural, v.46, n.10, p.1714-1722, 2016. http://dx.doi.org/10.1590/0103-8478cr20150534.

LUCHESE, C. L.; GURAK, P. D.; MARCZAK, L. D. F. Osmotic dehydration of physalis (Physalis peruviana L.): Evaluation of water loss and sucrose incorporation and the quantification of carotenoids. LWT - Food Science and Technology, v.63, p.1128-1136, 2015.

MIRANDA, D. S. A.; PESSOA, T.; GOUVEIA, J. P. G.; GURJÃO, F. F.; PINHEIRO, R. M. M.; MARTINS, A. G. L. A. Avaliação de textura e aceitação sensorial da passa de goiaba. Revista Tecnologia \& Ciência Agropecuária, v. 9, n. 4, p. 7-11, 2015.

MISSANG, C, E.; MAINGONNAT, J. F.; RENARD; C. M.; AUDERGON, J. M. Apricot cell wall composition: Relation with the intra-fruit texture heterogeneity and impact of cooking. Food Chemistry, v. 133, n. 1, p. 45-54, 2012.

OLIVARES, M. L. T.; VERKERK, R.; BOEKEL, M. A. J. S.; DEKKER, M. Thermal stability of phytochemicals, HMF and antioxidant activity in cape gooseberry (Physalis peruviana L.). Journal of Functional Foods, v. 32, p. 46-57, 2017. http://dx.doi.org/10.1016/j.jff.2017.02.021.

OZDEMIR, Y.; OZTURK, A.; TÜFEKÇI, S. Effect of two dipping pretreatment on drying kinetics of golden berry (Physalis peruviana L.). African journal of agricultural research, v.11, n.1, p.40-47, 2016.

PAGOT, E.; HOFFMANN, A. Produção de pequenas frutas no Brasil. In: SEMINÁRIO BRASILEIRO SOBRE PEQUENAS FRUTAS, 1, 2003, Vacaria. Anais. Vacaria. Embrapa Uva e Vinho, p. 9-14, 2003.

QUEIROZ, V. A. V.; BERBET, P. A.; MOLINA, M. M. B.; GRAVINA, G. A.; QUEIROZ, R. L.; DELIZA, R. Osmotic dehydration and convective drying of guava. Pesquisa Agropecuária Brasileira, v. 42, n. 10, p. 1479-1486, 2007.

SILVA, F. A. S.; AZEVEDO, C. A. V. The Assistat Software Version 7.7 and its use in the analysis of experimental data. African Journal Agricultural Research, v. 11, p. 3733-3740, 2016. https://doi.org/10.5897/AJAR 2016.11522.

SILVA, V. M. A; MELO, M. O. P.; ARAÚJO, A. J. B.; RIBEIRO, V. H. A.; SANTOS, N. C. Elaboration, microbiological study and texture profile of goat milk flavored with prune (Prunus domestica L.). Revista Craibeiras de Agroecologia, v. 4, n. 1, p. e7663, 2019.

\section{AGRADECIMENTOS}

Apoio financeiro: Fundação de Apoio à Pesquisa do Estado da Paraíba - FAPESQ. 